\title{
U.S. Social Justice Spaces and Global Justice: \\ Integrating International Students for the Engagement of All
}

\author{
Yuqing $\mathrm{Hou}^{1 *}$ and Amy Pojar ${ }^{1}$ \\ ${ }^{1}$ University of California, Los Angeles, USA \\ *Correspondence: yuqinghou@ucla.edu
}

\begin{abstract}
This qualitative study explores the extent to which international students integrate when they encounter social justice discussions inside or outside a U.S. class environment. Focusing on diversity courses at a west coast university, the study investigates international students' learning experiences as well as their contributions to these U.S. educational spaces when drawing from their perspectives and experiences from communities around the world. Because international students are both agents and objects of bias, the study hypothesizes that more integration leads to more engagement and better outcomes for both international and domestic participants. By interviewing and surveying students from varied national and social backgrounds, the study seeks to understand outcomes for a diverse group of both international and domestic students. The study's findings will advance policy, pedagogy, and practice conversations around internationalization, social justice education, and global citizenship education at institutions of higher education in the U.S.
\end{abstract}

Keywords: International students, integration, social justice, global citizenship, internationalization

\section{Introduction \& Literature Review}

During the last half-decade or so, an unprecedented number of international students studied at U.S. colleges and universities. The Institute of International Education (IIE) reported that for the 20182019 academic year, there are over one million international students in the U.S., which account for

Received August 29, 2020; revised October 7, 2020; accepted November 7, 2020; electronically published January 31, 2021 Journal of Comparative \& International Higher Education December, 2020, Vol. 12, No. 6S1, pp. 160-168.

DOI: $10.32674 /$ jcihe.v12i6S1.2880

(C) 2020 Journal of Comparative \& International Higher Education. All rights reserved. 
approximately $5.5 \%$ of the whole student population in higher education (IIE, 2019). With the growth of international students in the U.S. came an increase in studies on the population. Previous research on international students focused on their challenges in academic spheres as well as psychological and socio-cultural adjustment (e.g., Constantine et al., 2004; Mesidor \& Sly, 2016). Factors that contributed to international students' negative experiences of acculturation have mainly included language proficiency, racial discrimination (Hanassab, 2006; Lee \& Rice, 2007), communication styles (Oguri \& Gudykunst, 2002), social isolation (Hayes \& Lin, 1994), and cultural distance between the home and host culture (Lee \& Rice, 2007). However, many of these studies take a deficit-only approach to understanding international students' experiences and pay less attention to the learning they acquired or the contributions they make when navigating a variety of educational spaces in the U.S. Notably, very few studies focus on international students' experiences in social justice or global citizenship spaces. International students bring with them perspectives and experiences from around the world, including their perspectives about equity, diversity, and inclusion. Previous research illustrates that some international students may reproduce and reinforce stereotypes and bias towards students from minoritized groups, and therefore, may impact campus climate negatively. Ritter and Roth (2014) argue that international students who had limited exposure to the U.S. outside of depictions in the media will arrive with beliefs in racial hierarchies and bias toward certain groups, especially African American men. Similarly, Mitchell et al. (2017) found that international students hold limited knowledge about U.S. concepts of race; therefore, some students don't know why Americans "force race to be an issue" (p. 7). These findings are not surprising given that some of the top countries from which international students hail include relatively racially homogeneous countries such as South Korea and China (IIE, 2019).

Therefore, international student participation in social justice education could improve campus climate and teach international students about new ways to understand race and racism in the U.S. and the world. 
Yet international students are not only agents but also objects of bias. For example, international students experience racism and racialization within and beyond U.S. campuses, as well as experiences associated with injustices around gender, sexuality, class, ability, religion, language, etc. Additionally, the political climate up to and after the 2016 Presidential election changed the landscape of globalism, and therefore, the climate under which international students operated on U.S. campuses. The rise of xenophobia and extreme nationalist ideologies affected international students negatively in that they began dealing with "everyday landscapes of exclusion" (Pottie-Sherman, 2018, p. 35) and expressed concerns and even panic after the election. Some of them conveyed uncertainty and anxiety about finishing their education in the U.S. (Johnson, 2018).

Additionally, given that international students may be more familiar than U.S. students in discussing issues around equity, diversity, and inclusion in relation to their own country's or region's context, they have much to share and teach their peers. Consider experiences of students from India, a top country, according to IIE (2019), where class, ethnic, language, and religious diversity often occur as themes in the discourse around Indian politics. Consider immigration discourse in Europe, where Germany, for instance, invites more refugees than any other country in the West. Consider policies around gender equity in a country such as Iceland. Consider attempts at racial reconciliation in a country such as South Africa. These examples suggest that students from these countries may provide observations that can potentially broaden the perspectives of domestic students in the U.S., especially on issues related to equity, diversity, and inclusion. The integration of international students into social justice spaces means new possibilities arise for exchange and learning for domestic students about how social experiences both vary and look eerily similar around the world.

Therefore, full integration of international students into U.S. social justice spaces means: 1) international students will learn about the U.S. historical context as well as why and how American's problematize race and other social categories, which will provide opportunities to map these 
(potentially) new ways of thinking to other social issues across the globe, and 2) international students will enrich the learning of domestic students by incorporating their lived experiences, perspectives, and cultural capital (Yosso, 2005) from across the globe. Given the historical legacies of oppression and current social problems in the U.S., it is important to note that neither the U.S. nor its institutions of higher education hold a monopoly on social justice done well. Similarly, no other country holds this monopoly. This process of mutuality, then, is important for the learning of all participants in social justice spaces and courses, and we hypothesize that better integration of international students in these spaces means better outcomes for all students as well as their institutions of higher education.

\section{Theoretical Framework}

Theoretical frames associated with socio-cultural transitions can provide useful guidance on this underexplored area of the international student experience. Berry's (1997) acculturation model illustrates the ways in which one's original social, cultural, and psychological identity may change when adapting to a new environment. Assimilation, integration, marginalization, and separation constitute four predominant relationships that individuals may develop to a host culture (Berry, 1997). For international students, the model and four relationships help describe the possible outcomes when they encounter social justice spaces in the U.S. In the context of this study, integration means international students engage in discussions of social justice, bringing their lived experiences and insights, while also listening well to the perspectives of others and incorporating new information learned into their world view.

The postcolonial theory leads the authors to consider the ingrained imbalance of power relations and inequality between Global North and Global South in the process of globalization and thus helps us interpret the increasing internationalization in U.S. higher education with a critical eye. Therefore, we apply a postcolonial lens and aim to interrogate the "discursive basis of Western rule" (Tikly \& Bond, 2013, p. 423). Additionally, we aim to support student agency and mutual learning by 
adopting an emancipatory and engaged approach (Madge et al., 2009). We believe this application of postcolonial theory will call into question American exceptionalism and the 'us' and 'them' dichotomy. Therefore, our study will differentiate between experiences of international students from the Global North and those from the Global South and problematize American exceptionalism when expressed in social justice spaces.

In alignment with the postcolonial approach, the Global Citizenship Education (GCE) framework, especially its critical agendas (Andreotti, 2006), will also be employed to challenge inequality and hegemony in a global age. The critical mode of GCE denounces the unfairness and unsustainability of the current global structures and seeks to create participatory and transformative spaces for students to develop skills and dispositions required for an interconnected world. Incorporating the theory of critical GCE, the current study contends that all students could be active global citizens who make systemic changes at both local and global levels when participating in a space for social justice.

\section{Proposed Study}

While Ritter and Roth (2014) and Mitchell et al. (2017) propose utilizing intergroup dialogue spaces to push against stereotypes and biases international students hold about minoritized communities in the U.S., scant literature exists evaluating the integration of international students into these spaces and detailing their experiences there. Few studies seeking to understand international student experiences in diversity courses or initiatives in the U.S. exist. For example, Daniels (2010) found that diversity courses contribute to international students' diversity awareness and intergroup peer interactions. Burkhardt and Bennett (2015) found that diversity initiatives enhanced the presence of international students but led to the creation of 'us' vs. 'them' divides between U.S. and international students, since it does little to encourage cross-cultural interactions on a daily basis. However, these two studies lack specific attention to integration, which is the mechanism by which international students 
contribute to social justice spaces, and U.S. students learn from international student experiences in a mutual way.

This study uses semi-structured interviews (Seidman, 2013) and surveys of international students from the Global North and Global South, white students, as well as students of color who are from the U.S. to understand the following questions: 1) To what extent are international students integrated into diversity courses? What acculturation experiences are they having in these spaces (i.e., integration, marginalization, separation, assimilation)? 2) What do international students from the Global North and Global South learn from these social justice spaces about U.S. socio-cultural experiences? 3) What do white students and students of color from the U.S. learn from these social justice spaces about social experiences around the world? We aim to interview ten students of each type (40 students total) and recruit from diversity courses at a west coast university. The survey will go out to all participants in diversity courses at the same university for a given quarter or semester.

\section{Conclusion}

This important inquiry will contribute to the field of international higher education, and equity, diversity, and inclusion education by advancing several policy, pedagogy, and practice conversations around internationalization, social justice education, and GCE at institutions of higher education in the U.S. By centering international students' experiences in social justice spaces for the engagement of all, this study 1) illustrates how essential diversity and social justice education is to international education, GCE, and internationalization of higher education, 2) elicits reflection and action opportunities for professors, policy-makers, and practitioners involved in facilitating social justice education, and 3) prepares institutions of higher education to rethink their internationalization agendas to ensure meaningful learning experiences for all students.

Sound practices for integration of international students into social justice conversations will emerge from this study, which is an overlay to all the outcomes mentioned above. Requirements for 
diversity initiatives aim to provide all college students with cross-cultural awareness, experiences that reduce prejudice, and experiences that instill new perspectives about human difference (Humphreys, 1997). If we care about the intersection of equity, diversity, and inclusion education with international education, then we should infuse those values in every domain of the university, including social justice spaces. Doing so is the only way to ensure that all students, international and domestic, gain a more comprehensive understanding of human difference and human similarly around the world, which is necessary for all students everywhere in an increasingly globalized world.

\section{Author Note}

Yuqing Hou, PhD student in the Social Sciences and Comparative Education division of the Graduate School of Education and Information Studies at UCLA. She holds a BA in International Studies and Education Studies, and MA in Secondary Education, both from Brandeis University. Contact: yuqinghou@ucla.edu.

Amy Pojar, Assistant Director, Research \& Special Projects, UCLA Dashew Center for International Students and Scholars. Amy is a PhD candidate and holds an MA in Social Sciences and Comparative Education from the Graduate School of Education and Information Studies at UCLA. Contact: amy.pojar@g.ucla.edu.

\section{Reference}

Andreotti, V. (2006). Soft versus critical global citizenship education. Policy \& Practice: A Development Education Review, 3(Autumn), 40-51.

Berry, J. W. (1997). Immigration, acculturation, and adaptation. Applied Psychology, 46(1), 5-34. 
Burkhardt, J., \& Bennett, E. E. (2015). Shaping the Future of a Globalized World: A Qualitative Study of How Undergraduate International Students' Everyday Cross-Cultural Experiences Were Impacted by University Diversity Initiatives. European Journal of Training and Development, 39(3), 162-181.

Constantine, M. G., Okazaki, S., \& Utsey, S. O. (2004). Self-concealment, social self-efficacy, acculturative stress, and depression in African, Asian, and Latin American international college students. American Journal of Orthopsychiatry, 74(3), 230-241.

Daniels, S. G. (2010). The effect of diversity courses on international students from China and Hong Kong: A focus on intergroup peer relationships (Order No. 3418026). Available from ProQuest Dissertations \& Theses A\&I; ProQuest Dissertations \& Theses Global. (750445113). Retrieved from https://search.proquest.com/docview/750445113?accountid=14512

Hanassab, S. (2006). Diversity, international students, and perceived discrimination: Implications for educators and counselors. Journal of Studies in International Education, 10(2), 157-172.

Hayes, R. L., \& Lin, H. R. (1994). Coming to America: Developing social support systems for international students. Journal of Multicultural Counseling and Development, 22(1), 7-16.

Humphreys, D. (1997). General Education and American Commitments. A National Report on Diversity Courses and Requirements. Association of American Colleges and Universities.

Institute of International Education (IIE). (2019). Open Doors Data. New York: IIE. Retrieved from https://p.widencdn.net/6tpaeo/Open-Doors-Annual-Data-Release-2019-11-17-Print

Johnson, K. (2018). Opportunities \& anxieties: A study of international students in the Trump era. Lewis \& Clark Law Review, 22(2), 413-440.

Lee, J. J., \& Rice, C. (2007). Welcome to America? International student perceptions of discrimination. Higher Education, 53(3), 381-409. 
Madge, C., Raghuram, P., \& Noxolo, P. (2009). Engaged pedagogy and responsibility: A postcolonial analysis of international students. Geoforum, 40(1), 34-45.

Mesidor, J. K., \& Sly, K. F. (2016). Factors that contribute to the adjustment of international students. Journal of International Students, 6(1), 262-282.

Mitchell Jr, D., Steele, T., Marie, J., \& Timm, K. (2017). Learning Race and Racism While Learning: Experiences of International Students Pursuing Higher Education in the Midwestern United States. AERA Open, 3(3), 233285841772040

Oguri, M., \& Gudykunst, W. B. (2002). The influence of self construals and communication styles on sojourners' psychological and sociocultural adjustment. International Journal of Intercultural Relations, 26(5), 577-593.

Pottie-Sherman, Y. (2018). Retaining international students in northeast Ohio: Opportunities and challenges in the 'age of Trump'. Geoforum, 96, 32-40.

Ritter, Z., \& Roth, K. (2014). Realizing Race: Media Representations and the Uneasy Adjustment of Asian International Students and African American Males on US College Campuses. In Erbe, N. D. (Ed.), Approaches to Managing Organizational Diversity and Innovation (pp. 100-123). IGI Global.

Seidman, I. (2013). Interviewing as Qualitative Research: A Guide for Researchers in Education and the Social Sciences (4th ed.). Teachers College Press.

Tikly, L., \& Bond, T. (2013). Towards a postcolonial research ethics in comparative and international education. Compare: A Journal of Comparative and International Education, 43(4), 422-442.

Yosso, T. J. (2005). Whose culture has capital? A critical race theory discussion of community cultural wealth. Race Ethnicity and Education, 8(1), 69-91. 